\section{ANTINUCLEAR ANTIBODIES IN IU/ML PREDICTS DSDNA AND ENA ANTIBODIES}

C Bundell*, P Hollingsworth. PathWest, Clinical Immunology, Nedlands, Australia

\subsection{6/lupus-2017-000215.359}

Background and aims Results of the immunofluorescence (IIF) ANA test are commonly reported as positive or negative, and a titre is also reported. The test is not standardised. The value of the IIF ANA test has been questioned because of a large proportion of apparently false positive results. We show here that ANA quantified by estimation of immunofluorescence intensity calibrated against the ANA reference preparation WHO 66/233 is highly predictive of the occurrence of antidsDNA and anti-ENA in the same serum, and is therefore a cost efficient screening test for these antibodies.

Methods In a cohort of 85542 patients tested for ANA for the first time during the 11 years 2000 to 2010 , the $50^{\text {th }}$ percentile was $2 \mathrm{IU} / \mathrm{ml}$, the $90^{\text {th }}$ was $10 \mathrm{IU} / \mathrm{ml}$, the $95^{\text {th }}$ was $20 \mathrm{IU} / \mathrm{ml}$ and the $99^{\text {th }}$ was $30 \mathrm{IU} / \mathrm{ml}$. The relationship between ANA quantitated in $\mathrm{IU} / \mathrm{ml}$ with anti dsDNA and anti ENA (histones, RNP, SSB/La, Sm and, Scl70), in terms of percent predictive value and odds ratios are shown in Table 1 .

Results The predictive value was higher in younger individuals and females as shown in Table 2.

Conclusions ANA quantitated in $\mathrm{IU} / \mathrm{ml}$ and taking into account age and gender is an efficient screening test to select which sera require testing for anti dsDNA and anti ENA. It would permit this testing to be safely avoided in some $90 \%$ of sera.

\section{THE COMPARISON BETWEEN CHEMILUMINESCENT IMMUNOASSAY AND LINE IMMUNOASSAY FOR THE DETECTION OF ANTIBODIES SPECIFIC TO SLE DIAGNOSIS: A RANDOMISED, INDEPENDENT MULTI- CENTRE CLINICAL STUDY IN CHINA}

${ }^{1} \mathrm{X}$ Chen, ${ }^{2} \mathrm{C} \mathrm{Hu}$. ${ }^{1}$ Immuno-diagnostic Engineering and Technology, clinical immunology, Suzhou, China; ${ }^{2}$ Peking Union Medical College Hospital, Department of Rheumatology, Beijing, China

\subsection{6/lupus-2017-000215.360}

Background and aims Autoantibodies to Sm, dsDNA, Nucleosome (Nuc) and Ribosome P protein (Rib-P) are highly
Abstract 359 Table 2

\begin{tabular}{lcc}
\hline Age (years) & $\begin{array}{c}\text { \% dsDNAantibody }>\mathbf{1 0 I U} / \mathbf{m l} \\
\text { Male }\end{array}$ & Female \\
\hline \hline $0-<20$ & 2.9 & 4.9 \\
$20-<40$ & 2.8 & 4.8 \\
$40-<60$ & 1.4 & 2.2 \\
$60-<80$ & 1.6 & 1.9 \\
$\geq 80$ & 1.1 & 1.8 \\
\hline
\end{tabular}

specific to Systemic Lupus Erythematosis (SLE) diagnosis. We aimed to compare Chemiluminescent immunoassay (CLIA) platform (BioCLIA 1200) and Line ImmunoAssay (LIA) on the conformational detection of these SLE specific antibodies through a randomised, independent and multi-centre clinical study in China.

Methods A total of 717 samples suffered from systemic autoimmune diseases (SLE, $\mathrm{n}=535 ; \mathrm{SjS}, \mathrm{n}=99$; SSc, $\mathrm{n}=35$; RA, $\mathrm{n}=48)$ and healthy individuals $(\mathrm{n}=94)$ from 6 Tier-3 hospitals from China were tested with BioCLIA 1200 (HOB Biotech Group, Suzhou, PRC) and LIA (EUROIMMUN, Luebeck, Germany). Data were used to evaluate the test agreement between these two conformational assays. Discrepant samples were also retested by ELISA (EUROIMMUN, Luebeck, Germany) and analysed with different diseases panel.

Results The overall qualitative agreements between CLIA and LIA were 91.9\% (confidence interval, 95\% CI 90.0\%-93.7\%) for anti-Sm, $86.7 \%$ (95\% CI 84.3\%-89.0\%) for anti-dsDNA, $89.1 \%$ (95\% CI 87.0\%-91.3\%) for anti-Nuc, 89.3\% (95\% CI $87.7 \%-91.9 \%)$ for anti-Rib-P. The discrepant samples confirmed by ELISA test showed CLIA test data had a better correlation with ELISA.

Conclusions The BioCLIA 1200 (a Chemiluminescent immunoassay platform) showed good clinical performance in a large multi-centre clinical study for the detection of SLE specific autoantibodies to Sm, dsDNA, Nuc and Rib-P when comparing with LIA test method. With the additional benefit of full automation, random access and quantitative measurement, BioCLIA 1200 is an alternative to the traditional LIA test for the conformational test of SLE specific antibodies.

Abstract 359 Table 1

\begin{tabular}{lcccc}
\hline $\begin{array}{l}\text { ANA } \\
(\mathbf{I U} / \mathbf{m l})\end{array}$ & \multicolumn{2}{c}{ Anti dsDNA $>\mathbf{1 0} \mathbf{~ I U} / \mathbf{m l}$} & \multicolumn{2}{c}{$\begin{array}{c}\text { Anti ENA detected } \\
\text { OR }\end{array}$} \\
\hline \hline $\mathbf{0}-<\mathbf{5}$ & $0.6 \%$ & 1 & $\%$ & 1 \\
$\mathbf{5}-<\mathbf{7}$ & $1.0 \%$ & $1.65(0.72-3.79)$ & $18 \%$ & $1.55(1.24-1.93)$ \\
$\mathbf{7 - 1 0}$ & $0.8 \%$ & $1.34(0.72-2.48)$ & $18 \%$ & $2.58(2.04-3.26)$ \\
$>\mathbf{1 0}-\mathbf{2 0}$ & $2.3 \%$ & $3.94(2.18-7.12)$ & $26 \%$ & $6.34(5.07-7.93$ \\
$>\mathbf{2 0}-\mathbf{3 0}$ & $6.3 \%$ & $11.09(6.26-19.65)$ & $47 \%$ & $11.32(8.47-15.12)$ \\
$>\mathbf{3 0}$ & $17.9 \%$ & $35.61(19.92-63.62)$ & $61 \%$ & \\
\hline
\end{tabular}

